\title{
CONSIDERACIONES SOBRE LA DENOMINACIÓN DE ORIGEN COMO INSTRUMENTO PARA PROTEGER E IDENTIFICAR PRODUCTOS, EN ESPECIAL EL CASO DEL PISCO CHILENO
}

\author{
Rafael Areyuna Navarro
}

El presente es un estudio de los diversos aspectos que regulan el tema de las denominaciones de origen tanto en nuestro país como en el extranjero, poniendo énfasis en la realidad de la denominación que beneficia a uno de los productos más característicos de la Cuarta Región como es el pisco.

\section{PRINCIPALES ASPECTOS DE LAS DENOMINACIONES DE ORIGEN EN GENERAL}

Para el estudio del tema que nos ocupa es absolutamente necesario presentar el tema de las denominaciones de origen desde su perspectiva más general, ya que nos será muy difícil estudiar la especie pisco sin haber tratado antes el género denominaciones de origen.

\subsection{DEFINICIÓN DE DENOMINACIÓN DE ORIGEN}

La conceptualización de la institución en estudio, implica analizar lo que existe al respecto a nivel internacional, como nacional, ya que ambas realidades son absolutamente diferentes.

En el primer caso, existe una claridad plena respecto al significado que debe darse a este término, es así como el Artículo 2 del Arreglo de Lisboa relativo a la Protección de las Denominaciones de Origen y su Registro Internacional (1958), señala: "se entiende por denominación de origen, en el presente Arreglo, la denominación geográfica de un país, de una región o de una localidad que sirva para designar un producto originario del mismo y cuya calidad o características se deben exclusivamente o esencialmente al medio geográfico, comprendidos los factores naturales y los factores humanos".

El objetivo de este tratado es dar protección a las denominaciones de origen creando para tal efecto un sistema de registro que funciona en la Oficina Internacional de la Organización Mundial de la Propiedad Intelectual (O.M.P.I.), con sede en Ginebra.

No obstante la importancia del Arreglo de Lisboa para el desarrollo del tema, la última información oficial emanada de la O.M.P.I., señala que hasta 1997 solo 17 Estados eran miembros de este acuerdo, entre los cuales no figura Chile. 
Como es posible desprender del concepto, l 3 apelación de origen es un término técnico jurídico, ya que en él están amalgamados elementos propios de lo que es la Propiedad Intelectual y otros íntimamente ligados a la realidad de un pueblo. Estos dos aspectos son inseparables en la formación del concepto, por cuanto la institución en estudio es mucho más que una entelequia normativa; es más bien el reconocimiento de una realidad recogida por la norma, lo cual es, por cierto, una forma como el derecho trata de superar el típico retaguardismo que lo caracteriza.

Otro antecedente importante para tener mayor claridad en relación al concepto de las denominaciones de origen, es la recomendación que la Organización Internacional del Vino (O.I.V.) hizo a los gobiernos en 1947, la cual expresa "Un vino o un aguardiente puede llevar una Denominación de Origen solamente si ella está consagrada por el uso y un renombre constatado", este renombre debe resultar de caracteres cualitativos determinados por los factores naturales como el clima, tipo de suelo, cepajes, exposición, entre otros que permiten definir un área de producción limitada y por factores humanos, cuyo rol es también de la mayor importancia, al ser el hombre quien establece los métodos de cultivo y vinificación. En esta recomendación queda de manifiesto, con mayor claridad, los factores propios de la técnica vitivinícola que deben estar integrados al concepto de un Nombre de Origen.

A nivel nacional, la creación de un concepto se caracterizó por una primera etapa marcada por la intención del legislador de establecer con claridad el sentido de la denominación de origen, en este sentido, la Ley 17.105, publicada en el Diario Oficial el 14 de Abril de 1969, en su Artículo 12 letra i, define la denominación de origen como: " Aquella que identifica un producto vitivinícola por sus características específicas y por las regiones de que procede, las cuales se señalaran para cada caso. La denominación de origen no se podrá inscribir como marca comercial. ".

Con posterioridad cuando el legislador de 1985 decide derogar el libro primero de la Ley 17.105 , por medio de la Ley 18.455 , toma una actitud distinta y trata el tema de las denominaciones de origen sin definirlas.

Producto de esta poco afortunada regresión en los esfuerzos para dar una conceptualización precisa a la materia, cobra plena validez la primera parte del Artículo 20 del Código Civil, según el cual: " Las palabras de la Ley se entenderán en su sentido natural y obvio, según el uso general de las mismas palabras; pero cuando el legislador las haya definido expresamente para ciertas materias, se les dará en estas su significado legal." Por lo tanto frente a la actual falta de definición legal se hace aplicable como concepto de uso general la definición creada por el Arreglo de Lisboa.

En el mismo sentido el Artículo 21 del mismo cuerpo legal establece que las palabras de toda ciencia y arte se tomarán en el sentido que le dan los que profesan la misma ciencia o arte. Si entendemos que la vitivinicultura queda comprendida dentro de los conceptos de ciencia o arte, es claro que en esa área cobra plena validez la definición dada por el Arreglo de Lisboa y, obviamente, también lo señalado por la Organización Internacional del Vino.

Por lo anterior, es posible afirmar que en nuestra legislación cobran absoluta validez los conceptos antes señalados para definir la institución en estudio, esto es de vital importancia para toda la construcción teórica referente al tema; sobre todo si tenemos en cuenta que el mayor dinamismo en esta materia se logra a nivel internacional, de 
forma tal que si los diferentes Estados adoptan criterios uniformes será posible dar una verdadera protección a los productos favorecidos con las denominaciones de origen.

\subsection{CARACTERISTICAS DE LAS DENOMINACIONES DE ORIGEN}

El análisis de las características de las denominaciones de origen parte indudablemente de los conceptos de la misma y, además de como se ha desarrollado ésta en la práctica, por lo tanto no es posible pretender que existan características aplicables al tema que tengan valor universal. No obstante lo anterior, partiendo de que lo primordial en un nombre de origen es el medio geográfico, es posible inferir ciertos caracteres que, a la luz de nuestro Derecho, podríamos llamar de la esencia de las denominaciones de origen en general, esto sin perjuicio de que en el capítulo III tratemos en particular las características de la denominación de origen Pisco.

Estas características generales son:

a) Renombre o prestigio: Esta es una de las piedras angulares de las denominaciones de origen, ya que para que éstas puedan surgir es necesario que, previamente el producto beneficiado con las mismas haya adquirido una fama dentro de la comunidad que, le signifique un reconocimiento especial como una elaboración de categoría superior a otras de su género. Es este prestigio el que va tomando fuerza primero en forma consuetudinaria, hasta cobrar su pleno vigor al ser reconocido por el ordenamiento jurídico.

Conjuntamente con este renombre del producto y estrechamente ligado a él, se presenta la asociación con el lugar donde fue elaborado, factor que trataremos como segunda característica.

b) Naturaleza: Bajo este concepto quedan comprendidos los elementos suelo y clima, fundamentales para la fabricación de productos enológicos. Es justamente la especial conformación morfológica de un área determinada en unión con un clima especial lo que permite, específicamente en el caso del Pisco, el desarrollo de especiales variedades de vides que son utilizadas en el proceso productivo del mismo.

En este sentido, y como veremos más adelante, ha existido una acertada acción del legislador, al establecer cuales son las variedades de vides que sirven para la elaboración del Pisco en Chile.

c) Tradición: Con esta característica se pretende reconocer cuan importante es el factor humano en el campo de las apelaciones de origen, ya que es la transmisión de una generación a otra de las especiales formas de cultivo, cosecha, elaboración, un factor decisivo entre que el producto tenga una calidad u otra. En el fondo es el factor humano el que maneja lo que actualmente llamamos el "Know-How".

Este postulado es reafirmado con lo que expone el profesor Herbert Stupf ${ }^{1}$. quien al señalar las formas de manifestación del Know-How establece que en el ámbito técnico se presenta como fórmulas y recetas. Con esto nos queda claro, como este conocimiento ancestral cobra en nuestros días un valor no sólo simbólico, sino también económico. 
En esta misma característica, es necesario hacer una especial mención a los métodos de producción, ya que si bien estos forman parte de la tradición, es importante aclarar que no queda excluido de este concepto el avance técnico o tecnológico que experimenten los referidos métodos, muy por el contrario, estas innovaciones se complementan con las antiguas formas de elaborar, para ir creando un conocimiento siempre nuevo y así aumentar el valor del "Know-How" incorporado a la denominación de origen respectiva.

d) Reconocimiento oficial: Es propio de toda denominación de origen el tener un reconocimiento oficial, el cual tiene su más preclara vía de expresión en la Ley, aunque es factible que ciertos aspectos más técnicos queden reservados para reglamentos. El caso particular del Pisco es de esta guisa, ya que es la Ley 18.445 , que deroga el libro primero de la antigua Ley de Alcoholes, la que establece la denominación de origen Pisco y, por su parte el reglamento de dicha Ley, señala en su artículo 55 que, un reglamento especifico determinará las condiciones, características y modalidades que rigen esta materia.

\subsection{NATURALEZA JURÍDICA;}

Sin duda alguna, la determinación de la naturaleza jurídica de la denominación de origen es una de las tareas más delicadas del presente estudio, esto debido a que las consecuencias que derivan de inclinarse por una u otra teoría son muy diferentes. Lo anterior es importante si consideramos la aplicación práctica del tema en estudio y como pueden variar los derechos y las acciones de los titulares de una apelación de origen.

Para resolver el problema objeto de este parágrafo serán tratadas cuatro teorías que, enfocan el asunto desde perspectivas diferentes, tratando cada una de ellas, dar una mayor claridad sobre el tema.

\section{a) La denominación de origen como marca}

A este respecto cabe señalar que el objetivo final de una marca, es crear un fuerte capital comercial que beneficie directamente al producto individualizado con la misma. Para conseguir esta meta hay dos factores fundamentales: la identidad de la marca y su amplitud, entendida esta última como la cantidad de asociaciones que ésta puede generar. Justamente en relación con la identidad de la marca es que la denominación de origen cobra valor, ya que esta última encierra, conjuntamente con el origen geográfico del producto, elementos como autenticidad, tradición, calidad y personalidad. Por todo esto es que, se ha postulado por algunos autores que la denominación de origen es una marca comercial de carácter público.

Esta nueva teoría, parte haciendo una revisión de la concepción tradicional de marca, que se entiende como el nombre, término, signo, símbolo, diseño o combinación de ellos cuyo objetivo es identificar los bienes y servicios de un vendedor o grupo de vendedores con el objetivo de diferenciarlo de sus competidores. Frente a este concepto se ha pretendido que el mismo únicamente tiene sentido si consideramos que en sus orígenes, la marca realizaba la función de identificación del producto, a modo de información vital que facilitara el proceso de compra. 
Establecida con claridad la forma como está considerada la marca para esta teoría, es posible relacionarla con las denominaciones de origen, ya que actualmente los hábitos de consumo han originado una demanda hacia productos de mayor calidad que, puedan ser diferenciados de una forma nítida para así servir de mejor manera a la satisfacción de necesidades. Es justamente en este contexto, que surge la denominación de origen como una de las formas más tradicionales para establecer la personalización diferenciada de los productos. De modo más especifico, podemos decir, que ha sido en el mercado de los productos vitivinícolas donde la utilización y el desarrollo de la institución en estudio ha sido más extenso.

Así pues, desde la perspectiva del marketing, el nombre geográfico protegido mediante una denominación de origen, se configura como una marca colectiva pública; entendiendo por marca colectiva " aquella que se concede a entidades o asociaciones que tengan como finalidad garantizar el origen, naturaleza o calidad de determinados productos o mercancías, contando con la facultad de conceder el uso de las propias marcas a los empresarios que pertenezcan a la entidad o asociación" ${ }^{2}$. Según la definición en este tipo de marca se da un acceso restringido no sólo por el origen, sino también por los requisitos que se imponen a la naturaleza y a la calidad de los productos que se encuentran bajo su amparo y, sobre todo por el control que pueda imponer la institución que tiene la titularidad de la marca.

Conjuntamente con este supuesto de la marca colectiva pública algunos han sostenido la teoría de la "marca notoria", la cual tiene su origen en una interpretación amplia de la Convención de París de 1883. Según esta idea, dicha Convención da protección, no sólo a las marcas comerciales, sino que también a los nombres comerciales y a otros simbolos que se encuentren en esa categoría.

Con respecto a esta tesis, es válido sostener una crítica, ya que el citado acuerdo internacional establece en su artículo primero número 2 todas aquellas materias a las que alcanza la protección otorgada por la propiedad industrial y, entre estas nombra expresamente a las indicaciones de procedencia o denominaciones de origen. Por lo tanto, si existe una referencia precisa a las materias protegidas y entre ellas está mencionada la que nos interesa de una manera particular, pareciera inoficioso tratar de hacer interpretaciones que más que aclarar el tema lo enturbian aún más.

En general, cualquier teoría que pretenda reducir las denominaciones de origen al tema de las marcas, está pasando por alto algunas características propias de estas últimas y que no se dan en las primeras.

En relación con las marcas, se ha establecido la inscripción de las mismas, como el requisito básico para otorgarles una adecuada protección, de otra forma no podria ser este un tema pacífico frente a intenciones contrapuestas de ostentar la misma marca. Ante ello, el desarrollo de las apelaciones de procedencia ha sido totalmente ajeno a todo sistema registral, obteniendo siempre un reconocimiento y protección sin necesidad de inscripciones.

No obstante lo anterior, y sin que la crítica pierda validez, actualmente se hacen esfuerzos para crear un registro internacional para las denominaciones de origen, el

2 ASCARELLI, Tullio, Teoría de la concurrencia, pág. 478, Editorial Bosch, Barcelona 1960. 
cual no ha tenido mayores éxitos, sobre todo por la poca cooperación que los países desarrollados prestan al tema.

Por otro lado, es propio de las marcas, el que éstas sean bienes de propiedad de una empresa o establecimiento determinado, incluso de una persona natural, lo cual permite que puedan ser objeto de negociaciones jurídicas separadas del bien al que individualizan, v.gr. es perfectamente posible que una empresa de quesos venda una marca que individualiza a una determina variedad de su fabricación y, esta marca sea usada por otra empresa para identificar una línea de jugos de fruta.

Muy por el contrario, las denominaciones de origen son accesorias al producto que identifican $y$, no pueden ser objeto de negociaciones separadas de dicho producto, v.gr. ninguna empresa de las que elaboran Pisco podría pretender vender este vocablo como marca para ser utilizado para definir otro producto.

En la línea de lo anterior, y como clara diferencia entre ambas instituciones, es que toda denominación de origen debe valerse de una marca comercial para entrar al mercado. En el caso particular de nuestra legislación, la Ley $19.039^{3}$ que establece las normas aplicables a los Privilegios Industriales y Protección de los Derechos de Propiedad Industrial, señala en su artículo 20, letra e) que no pueden registrarse como marcas entre otras, las expresiones empleadas para indicar el origen, nacionalidad o procedencia de los productos o servicios a los cuales se aplicará la marca.

Para terminar el punto y, como anotación válida para cualquier supuesto sobre la naturaleza jurídica, es siempre mejor aquel postulado que logra hacer una clara y precisa determinación de la materia analizada y, no aquel que trata de confundirla o fusionarla con otra distinta.

\section{b) La denominación de origen como bien inmaterial}

Para poder explicar esta teoría es necesario tener presente la división clásica entre bienes corporales e incorporales, ya que entre estas dos clases surge, para algunos, una tercera que es la de los bienes inmateriales o también llamados intelectuales.

Fue el jurista romano Gayo, el que dio a conocer por primera vez una teoría netamente jurídica que diferenciaba entre cosas corporales e incorporales. Ya antes este tema había sido tratado principalmente desde el punto de vista filosófico. Gayo trata este tema en su obra Instituciones de la siguiente forma: " Por lo demás, algunas cosas son corporales y algunas incorporales. Corporales, las que pueden ser tocadas, como un fundo, un esclavo, la vestimenta, el oro, la plata y en fin otras innumerables. Son incorporales las que no pueden ser tocadas, las cuales son aquellas que tienen su fundamento en el derecho, como la herencia, el usufructo, las obligaciones contraidas de cualquier manera. Ni viene al caso que en una herencia se contengan cosas corporales, ni que aquello que nos es debido por una obligación la mayoría de las veces sea corporal, como un fundo, un esclavo, dinero; pues el derecho de la sucesión misma y el derecho

3 Publicada en Diario Oficial N 33.877, de 25 de Enero de 1991. 
del uso y el disfrute mismo y el derecho de obligación mismo es incorporal. en el mismo número están los derechos de los predios urbanos y rústicos..." 4

En este párrafo, Gayo nos presenta una clasificación de las cosas teniendo como criterio diferenciador el si las cosas pueden ser tocadas o no serlo y, agrega que en el segundo de los casos, es decir aquellas cosas que no pueden ser tocadas y por lo tanto incorporales, es necesario que estas tengan su fundamento en el derecho (iure consistunt).

Fiel a la tradición Romana, nuestro Código Civil (C.C.) ha recogido puntualmente la clasificación hecha por Gayo, es así como en el Artículo 565 del C.C. se hace una clasificación de los bienes en corporales o incorporales, siendo los primeros aquellos que tienen un ser real y pueden ser percibidos por los sentidos, poniendo como ejemplo una casa, un libro. Por otro lado señala que los incorporales, son aquellos que consisten en meros derechos, como los créditos y las servidumbres activas. Hasta aquí no existe una mayor novedad a lo planteado por Gayo en el siglo II después de Cristo, nuestro derecho ha hecho una clasificación de las cosas en el mismo sentido en que lo hizo este gran jurista.

Frente a este aparente estancamiento, surge la teoría de los bienes inmateriales o intelectuales. Esta pretende establecer una nueva categoría de bienes representada por todas las creaciones de la inteligencia humana o los valores emergentes de signos distintivos, que no son cosas corpóreas ni prestaciones de otras personas, pero cuya utilización representa un valor patrimonial y están dotados de una autonomía conceptual.

Con este postulado es posible hacer frente a aquellos que creen que las denominaciones de origen podrían ser cosas incorporales, basados en que según la clasificación tradicional serían de aquellos bienes que no se pueden tocar. Esto no es así, por cuanto las cosas incorporales corresponden a derechos, los cuales en nuestro ordenamiento jurídico se dividen en reales y personales, no pudiendo quedar comprendida en ninguna de estas categorías una entidad como la denominación de origen. Con respecto a esto, es necesario tener cuidado con no confundir los derechos que puedan emanar de una denominación de origen, con esta misma.

Para el profesor Alejandro Guzmán Brito es posible hacer un segundo reparo a esta intención de comprender la institución en estudio, además de otras creaciones del ingenio humano, en la categoría de bienes incorporales. Este autor señala que es una característica propia de estos bienes, el ser creaciones del derecho, al cual deben su consistencia; por lo tanto, al ser las creaciones del intelecto obras de su autor, obviamente no lo son del derecho. No obstante esto, es posible advertir que en el caso particular de las denominaciones de origen, éstas tiene un reconocimiento legal, lo cual puede ser visto como una creación del derecho y por lo tanto estaría cumpliendo el requisito para ser un bien incorporal.

En definitiva, la función del derecho, en esta materia, es la de advertir una realidad ya existente y que necesita protección, recordemos que al tratar los conceptos de

4 Fragmento de las Instituciones de Gayo obtenido de la obra de Alejandro Guzman Brito, Las cosas incorporales en la doctrina y en el derecho positivo. Editorial Juridica de Chile, primera edición 1995. 
las denominaciones de origen en ningún momento se exigía que fueran creadas por una Ley, sí debemos reconocer que es una característica común el que actualmente estas instituciones están amparadas por la Ley, pero en el hecho no son creadas por ésta.

Como último antecedente en relación con esta teoría, cabe citar lo que señala nuestra legislación en particular. En este sentido, el Código Civil establece en su artículo 584 que "Las producciones del talento o del ingenio son una propiedad de sus autores ". Es criterio común entre la doctrina que en este artículo nuestro código se esta refiriendo a la propiedad intelectual e industrial y dentro de esta última queda comprendida la denominación de origen. El citado artículo señala en su inciso segundo que " Esta especie de propiedad se regirá por leyes especiales ". Cabe señalar que el citado artículo 584 al referirse a las leyes especiales que regulan esta materia, presenta un pie de página en el que se indican las leyes que sobre el particular deben ser consultadas y entre éstas figura el Convenio de París para la Protección de la Propiedad Industrial, dicho convenio al señalar los objetos de protección incluye a las denominaciones de origen; por lo tanto, y en virtud de la referencia contenida en el artículo 584 del Código Civil, las denominaciones de origen forman parte de esta "especie de propiedad".

Por lo anterior, es posible interpretar que si existe una "especie de propiedad" es porque está referida a una "especie de bienes" distinta de las que ya han sido tratadas hasta ese momento en la obra de Bello, en relación con lo cual cabe señalar que al tratar este tema en el Código Civil, ya han sido tratados los bienes corporales e incorporales en un título anterior.

Con relación a este análisis, partiendo de la base que la denominación de origen reviste la naturaleza jurídica de un bien inmaterial o intelectual, es necesario establecer que como todo bien, ésta reporta una utilidad al hombre y es objeto, como ya se ha dicho, de una especie de propiedad. El problema se presenta al establecer quién es el titular de dicho derecho y cuales son las facultades que éste otorga. Es bueno señalar que estas interrogantes son un verdadero inconveniente en el tema de las denominaciones de origen, por cuanto en relación con las demás creaciones del intelecto, como por ejemplo una canción, una obra literaria o bien un modelo de utilidad, es claro quien es el autor y por lo tanto el propietario de la obra.

Partiendo de la base que la denominación de origen es un bien inmaterial o intelectual, es necesario analizar como se presenta el dominio en dichos bienes. Según el artículo 582 del Código Civil el dominio es el derecho real en una cosa corporal, para gozar y disponer de ella arbitrariamente; no siendo contra la ley o contra el derecho ajeno. Coincidente con esto el artículo siguiente del citado cuerpo legal, establece que sobre las cosas incorporales hay también una especie de propiedad y cerrando el ciclo está el artículo 584 que ya ha sido estudiado.

La definición del dominio que da el Código Civil nos habla de derechos reales, los cuales según el artículo 577 del mismo, son aquellos que tenemos sobre una cosa sin respecto a determinada persona. Con esta definición para algunos podría presentarse la duda si es posible concebir el derecho real de dominio sobre un bien inmaterial. Esta interrogante surge ya que el artículo 577 citado, se refiere a que los derechos reales, como el dominio, recaen sobre "cosas" y como ya se ha señalado, en nuestra legislación estas cosas pueden ser corporales o incorporales. 
Para resolver esta problemática, es necesario recordar que nuestro Código Civil cuando está tratando el dominio en los artículos 582 y siguientes, lo refiere, primero a los bienes corporales, luego a los incorporales y por último habla de una especie de propiedad sobre las producciones del ingenio o del talento, las cuales son claramente bienes inmateriales. Más aún, si consideramos, como debe ser, que dentro de estas producciones está contemplada la propiedad industrial y dentro de ésta, a las denominaciones de origen, la garantía del derecho de propiedad sobre esta clase de bienes está consagrada en la Constitución Política de 1980, en su artículo 19, número 25 , inciso tercero.

A mayor abundamiento, cabe citar a la doctrina para la cual la propiedad sobre los bienes inmateriales o también llamados intelectuales no merece dudas. En este sentido el profesor Alejandro Guzmán Brito en su obra Las cosas incorporales en la doctrina y el derecho positivo, señala "... la moderna doctrina ha arribado al parecer de que lo aquí llamado "cosas intelectuales" son precisamente objetos dotados de una autonomía conceptual, que pueden ponerse en paralelo con las cosas corporales (y con las incorporales habría que agregar)." En virtud de esta apreciación hecha por el profesor Guzmán, nos es posible ratificar que no habría problema para que los bienes inmateriales sean objeto del derecho real de dominio, al igual que las corporales o incorporales. Coincidente con esto, en la obra Derecho civil, parte preliminar y parte generaf. redactada por Antonio Vodanovic $\mathrm{H}$. basado en las versiones de clases de los profesores Arturo Alessandri R. y Manuel Somarriva U., se señala "La teoría clásica sostiene que el objeto del derecho real debe ser necesariamente una cosa corporal; pero las tendencias modernas admiten que también puedan serlo las cosas incorporales o derechos y los bienes inmateriales". El párrafo siguiente dice que "Según ciertos autores, el derecho real puede recaer: a) sobre cosas corporales; b) sobre derechos o cosas inmateriales, como el usufructo de derechos; c) sobre bienes inmateriales, como las producciones del talento é ingenio (propiedad intelectual, industrial, etc.); d) sobre universalidades, sean de hecho (un establecimiento comercial), sean de derecho, como una herencia ".

Con todo esto queda plenamente demostrado que nada obsta a que se pueda detentar la propiedad sobre los bienes inmateriales. Justamente en relación con esta posibilidad de tener el dominio de un bien inmaterial, es que se hace necesario establecer quien será el titular del mismo, ya que, como todo derecho real, en el dominio debe haber un sujeto activo que tiene la facultad de aprovechar el bien objeto del mismo. Como se ha señalado anteriormente, en el caso de bienes inmateriales que conforman el denominado derecho de autor, la situación se presenta más pacífica, por cuanto es precisamente el autor de la obra quien detenta el dominio de la misma. Igual cosa pasa en las instituciones más típicas de la propiedad industrial, será quien inscriba una mar$\mathrm{ca}$ o bien quien patente un invento, el que tenga el dominio sobre los mismos.

En el caso específico de las denominaciones de origen, se presenta una mayor complicación al momento de establecer quien es el sujeto activo del dominio sobre dichos bienes inmateriales. Se puede afirmar que de una manera genérica los titulares de la denominación son todos los habitantes de la zona geográfica en la cual se produce - elabora el producto amparado. El problema de esta afirmación está representado por el hecho que el tráfico jurídico relacionado con las denominaciones de origen se vería

5 Obra impresa por Editorial Conosur, Chile, 1991, pág 48. 
muy entorpecido o sería prácticamente imposible si el dominio sobre dicho bien se pretendiera ejercer por un grupo heterogéneo de personas.

La solución al problema planteado, pasa por diferenciar entre los titulares del dominio sobre la denominación de origen como un bien inmaterial y aquellos, que de una forma o de otra participan de la existencia de una denominación de origen. Siguiendo este razonamiento, es posible decir que se pueden considerar sujetos activos del dominio sobre el bien inmaterial que constituye una denominación de origen, los productores del bien amparado por dicha institución, que se encuentren debidamente individualizados según la legislación de cada país. Mientras, que la comunidad en general, puede ser considerada como un titular mediato de la denominación de origen, ya que si bien se beneficia de la misma, no tiene una intervención directa en todas las gestiones derivadas de la existencia de dicha institución.

Una vez establecido que, es posible tener dominio sobre un bien inmaterial y entregados algunos parámetros para determinar a los titulares de dichos bienes, específicamente en el caso de las denominaciones de origen; es conveniente revisar como se presentan las facultades del dominio en esta clase de bienes.

No está de más señalar que, la importancia natural de ser el dueño de un bien, está representada por la posibilidad de poder hacer algo con dicho bien, situación que en términos jurídicos está representada por las facultades del dominio.

Estos atributos o facultades de los que se encuentra revestido el dominio son tres, siendo el primero de ellos el derecho a usar (jus utendi), el cual consiste en utilizar la cosa conforme corresponda a su naturaleza. En segundo lugar, está el derecho a gozar (jus fruendi), esta facultad representa la posibilidad de poder disfrutar la cosa. Este goce puede ser natural, por ejemplo, cuando se trata de los frutos de un huerto, o jurídico, por ejemplo, cuando se refiere a una renta de arrendamiento. Por último, esta el derecho a disponer (jus abutenti), el cual se puede ejercer de forma jurídica, como cuando se enajena o se grava una cosa, o bien se puede ejercer en forma natural, como cuando se destruye o transforma un bien.

Es tal vez, en este aspecto que el dominio sobre los bienes incorporales presenta mayores diferencias con respecto al mismo derecho real aplicado en otros bienes.

Con relación a la facultad de usar el bien, no existe mayor diferencia a la situación que existe para otra clase de bienes. En el caso que nos preocupa de las denominaciones de origen, la facultad a usarla estará representada por el derecho que tienen los productores del bien amparado para identificar su producto específico agregando a su marca comercial la denominación creada para el bien.

Las especiales características de los bienes inmateriales, influyen notoriamente en que la facultad de gozar del bien tenga algunas diferencias. Incluso para algunos esta facultad estaría totalmente anulada por cuanto dichos bienes no tienen la capacidad de producir frutos naturales o civiles que gozar. Frente a esto hay que considerar la posibilidad que el goce del bien inmaterial esté dado por la posibilidad de reproducir la obra o bien de aplicar un invento en un proceso productivo.

En cuanto a las denominaciones de origen, cabe la posibilidad de que se produzca un goce de las mismas como producto de alguna gestión comercial que puedan desarrollar los titulares de dicho bien, por ejemplo, en México, los particulares pueden usar 
las denominaciones de origen en virtud de una autorización expedida por la Secretaría de Industria y Comercio. Una vez que la han obtenido, están facultados para otorgar licencia de uso a un tercero que venda o distribuya sus productos, es perfectamente posible, por que la ley no lo prohibe, que dicha licencia de uso sea objeto de un contrato de arrendamiento.

Por último, en cuanto a la facultad de disponer de los bienes inmateriales es criterio uniforme que este atributo no está presente en el dominio de dichos bienes, por cuanto estos son inmodificables o indestructibles, cualquier alteración de los mismos implicaria haber creado un nuevo bien distinto al anterior. En el caso de las denominaciones de origen, esta es una realidad que se ve con mayor fuerza, por cuanto cuando estas son reconocidas por la ley, la misma se encarga de restringir su uso a una determinada área geográfica, por lo que los productores beneficiados no podrían pretender enajenar la denominación que los favorece, a personas que elaboren un producto similar en una región distinta a la comprendida dentro de la zona de protección.

Estos temas serán revisados en esta obra al tratar la situación especifica del Pisco chileno como una denominación de origen.

Por todo lo antes expuesto, es posible afirmar que la teoría de los bienes inmateriales es la que mejor refleja la naturaleza jurídica de las denominaciones de origen, lo cual no es un total alivio, ya que es necesario que la doctrina profundice en el estudio de los bienes inmateriales para saber cuales son lạs verdaderas implicancias de éstos en nuestro ordenamiento jurídico.

Sin perjuicio de tener una opinión o más bien una preferencia en cuanto a teorías, es bueno revisar dos más de ellas para así tener una visión más clara del asunto que nos inquieta.

\section{c) La denominación de origen como forma especificada de propiedad industrial}

La propiedad industrial es una rama de lo que se conoce como propiedad intelectual, que además esta formada por el derecho de autor. El objetivo de esta propiedad industrial es otorgar protección a ciertas y determinadas creaciones del hombre. En términos más específicos, y siguiendo los postulados de Vladimir Garcia-Huidobro Amunátegui ${ }^{6}$, este tipo de propiedad trata de la protección de las invenciones, los dibujos o modelos industriales, el nombre comercial, las marcas de fabrica o de comercio, las denominaciones de origen y las indicaciones de procedencia y de la represión de la competencia desleal.

Según lo expuesto, las denominaciones de origen estarían incluidas en la propiedad industrial, por lo que para algunos esta pasa a ser una forma determinada de dicha propiedad, explicando así su naturaleza jurídica. Este argumento es criticable, ya que si bien no cabe duda que las denominaciones de origen son parte de la propiedad industrial, no es tan cierto que su naturaleza jurídica se pueda explicar tan sólo por este hecho. Coincidente con la idea señalada al final de la letra a) de este apartado, parece

6 GARCIA-HUIDOBRO AMUNÁTEGUI,Vladimir, Legislación sobre propiedad industrial, análisis jurisprudencia y guia práctica, Editorial Jurídica de Chile, Santiago, 1992. 
que, siempre es bueno que, todo postulado logre dar claridad sobre un tema y, no simplemente tratar de reducir el problema a la alternativa más cercana posible.

Superando la crítica, lo importante de esta teoría es que otorga una certeza respecto a qué rama especifica del Derecho pertenecen las denominaciones de origen, ya que de esta forma hay claridad sobre la legislación aplicable y sobre el tratamiento que debe recibir.

\section{d) La denominación de origen como un estímulo económico}

Es sabido que una de las actuales herramientas que tiene el Estado para incentivar el desarrollo de ciertas actividades son los estímulos económicos, ya sea que estos se presenten como franquicias tributarias, subsidios, beneficios crediticios, etc.

Considerando estas formas de intervención indirecta del Estado, es que se ha postulado que las denominaciones de origen constituyen un estímulo económico, esto debido a la exclusividad de elaboración que éstas confieren a los productores de la zona beneficiada, lo que llevaría a que gran cantidad de capitales se moviera hacia esas zonas, generando más trabajo e inversión en ellas.

No obstante que lo anterior es una realidad, cabe señalar que la existencia de estas circunstancias económicas, no implica que se pueda determinar la naturaleza jurídica del instituto en análisis por su sola concurrencia. Este hecho de ser una forma de estímulo económico, más bien aparece como una característica propia de las denominaciones de origen. En efecto no podría ser de otra manera, ya que, la exclusividad de producción es inseparable de la idea de denominación de origen y, como es propio de la lógica de mercado, si se tiene la posibilidad de producir " monopólicamente " se considerará a la actividad que otorga esta garantía como más rentable y se destinarán más recursos a ella.

Por lo tanto, más que determinar su naturaleza juridica, el ser una forma de estímulo económico es una característica propia de toda denominación de origen y esto debido, como ya explicamos, a la exclusividad de producción.

\section{DENOMINACIÓN DE ORIGEN PISCO}

Una vez conocidos los aspectos que caracterizan a todas las denominaciones de origen, ya contamos con las herramientas para conocer en particular la denominación que favorece al pisco chileno. En este acápite no serán tratadas escasas normas jurídicas que se refieren al tema, que actualmente no pasan de ser la Ley 18.455 que fija normas sobre producción, elaboración y comercialización de alcoholes etílicos, bebidas alcohólicas y vinagres, publicada en el diario Oficial $\mathrm{N}^{\circ} 32.318$, de 11 de Noviembre de 1985 y su Reglamento, aprobado por Decreto Supremo No 78 del Ministerio de Agricultura, de fecha 31 de Julio de 1986, publicado en el Diario Oficial N 32.604 de 23 de Octubre de 1986.

No obstante lo anterior, es imprescindible citar la forma como la referida Ley 18.455 define en su artículo 28 la denominación de origen pisco " esta denominación queda reservada para el aguardiente producido y envasado, en unidades de consumo. en las Regiones III y IV, elaborado por destilación de vino genuino potable, proveniente 
de las variedades de vides que determine el reglamento, plantadas en dichas Regiones." Esta definición legal permite hacer todo un desarrollo en torno al tema del pisco como una denominación de origen, pero cabe hacer notar que cualquier intento sistematizador en esta materia no pasa de ser elaboración doctrinaria, motivada principalmente por los caros intereses de los productores de pisco, ya que por la vía legislativa se ha perdido el brío otrora se tuvo en relación al tema.

\subsection{CHILENIDAD DE LA DENOMINACIÓN PISCO}

Como se desprende de la evolución normativa chilena, actualmente es posible afirmar que Pisco es una denominación de origen en Chile, y como tal debe ser entendida y tratada tanto en el ámbito interno como en el internacional. Frente a este punto ha surgido discusión respecto a la autenticidad de nuestra denominación, sobre todo por una curiosa coincidencia con el caso de un aguardiente elaborado en Perú que ostenta la misma denominación. Respecto al punto, cabe señalar que no es el ánimo del presente trabajo dilucidar esta controversia, pero sí, aportar algunos antecedentes que sirvan como base de análisis en el tema.

Se ha dicho que a nuestra denominación la faltaría en sus comienzos la referencia a un territorio determinado del cual adoptaría el nombre. Frente a esto cabe señalar que desde 1936, existe en la antigua provincia de Coquimbo, hoy Cuarta Región de Coquimbo, específicamente en la Provincia de Elqui, comuna de Paihuano, un pueblo llamado Pisco Elqui. En el señalado año y por la Ley $N^{\circ} 5,798^{7}$, se declara que el pueblo de La Unión del Departamento de Elqui, se denominará "Pisco Elqui ". Por lo tanto, existe un sustento territorial para la conformación de la denominación Pisco, lo cual cobra mayor fuerza si consideramos que fue recién en 1969, con la dictación de la Ley 17.105 que se da un reconocimiento oficial a la denominación de origen Pisco en nuestro pais.

Algunos han querido restar importancia a este antecedente por cuanto, antes de 1936 el nombre del pueblo citado era La Unión. No obstante lo anterior, este contra argumento pierde validez si se tiene en cuenta que el cambio de nombre del pueblo obedece justamente a una política de Estado destinada a crear un sistema de protección a la industria pisquera, el cual debía ser concordante con la doctrina de la época, la cual era muy estricta en cuanto a los requisitos de una denominación de origen. Además, se debe considerar que desde muy antiguo se fabricaba el Pisco en el valle del Elqui, prueba de ello es que la Ley $4.536^{\circ}$. Sobre Alcoholes, establece en su artículo 35, al referirse al impuesto que deben pagar los licores, que "Los aguardientes no aromatizados, y los Piscos y cognacs naturales, pagarán solo la mitad del impuesto establecido en el inciso precedente, siempre que sean embotellados por el destilador que los produzca". Además, el mismo artículo en su inciso tercero señala que "Se entenderán por aguardientes no aromatizados, Piscos y cognacs naturales, únicamente los que sean genuinamente puros y obtenidos de la uva o sus derivados, sin agregados de esencias ni otras substancias que las permitidas por el reglamento".

\footnotetext{
$7 \quad$ Ley publicada en el Diario Oficial $N^{\circ} 17.382$, de $1^{\circ}$ de Febrero de 1936.

8 Publicada en el Diario oficial Ne 15,276, de 18 de enero de 1929.
} 
En relación con lo anterior, cabe señalar que actualmente se ha establecido en Europa una doctrina que reconoce las llamadas "Denominaciones tradicionales ". Estas han surgido, justamente, en sector de las aguardientes donde existen denominaciones que son indicativas de un origen, pero que no están compuestas de un nombre geográfico. Esta doctrina ha establecido que dichas denominaciones tradicionales deben tener la misma protección que las denominaciones de origen. Coincidente con esta idea, el proyecto de ley tipo sobre denominaciones de origen para países en desarrollo, elaborada por la O.M.P.I., en 1975, proponía dar protección a las denominaciones que sin corresponder a un lugar o a una región, en el fondo sin tener un vínculo geográfico directo, han adquirido tal carácter en forma consuetudinaria. Ejemplos de esta realidad pueden ser el Xabentún, bebida mexicana identificada plenamente con la península de Yucatán, pero cuyo nombre no corresponde a ninguna región o localidad de dicha península. En el mismo caso esta la Cava española, que es tomada como una denominación de origen, pero cuyo nombre no hace alusión a ninguna región o zona que exista en España, sino que, dicha nombre esta tomado de las cavas, que son las bodegas subterráneas donde se guardan los vinos y, que por extensión se aplica a este vino espumoso español elaborado según el método de la champaña.

De lo anterior, es posible concluir que a la luz de la actual doctrina, la denominación de origen Pisco tiene en Chile el carácter de tal, ya sea por la vía directa en vinculación con el poblado de Pisco Elqui o bien por la vía de ser una denominación tradicional. Además de todo este referente doctrinario cabe señalar, que no hay duda alguna que dentro de nuestro ordenamiento jurídico, Pisco es una denominación de origen, pues así lo ha establecido la ley, y como sabemos, nadie puede alegar ignorancia de la ley después que esta haya entrado en vigencia.

\subsection{CARACTERÍSTICAS DE LA DENOMINACIÓN DE ORIGEN PISCO}

La denominación de origen Pisco comparte plenamente las características que fueron estudiadas en el capitulo primero en relación con la denominación de origen en general, por tanto se estudiarán ahora los elementos que son típicos en la denominación Pisco.

En este sentido las características de la denominación de origen Pisco son:

\section{a) Goza de reconocimiento oficial}

No obstante que, las denominaciones de origen surgen como un hecho, que se verifica en la realidad en el reconocimiento por parte de los consumidores de la calidad de un determinado producto, estando basado éste en las especiales características de suelo, clima, técnica, cultura y factores humanos que intervienen su elaboración; estas apelaciones de origen sólo cobran una verdadera existencia para el ordenamiento jurídi$\mathrm{co}$, al ser reconocidas por éste.

En toda estructuración del derecho, siempre ha existido la tendencia a establecer una jerarquía entre las normas que conforman un determinado ordenamiento $y$, como consecuencia de esta graduación, las materias que quedan regidas por uno u otro tipo de normas dentro de esta escala, adquieren una importancia conforme al precepto que las establece. 
Toda esta introducción, - obvia para las personas involucradas con el estudio del Derecho -, ha sido hecha en función de resaltar la vía por la cual se ha establecido la denominación de origen Pisco, a diferencia de lo que puede suceder con futuras denominaciones de origen. Al respecto cabe señalar el artículo 27 de la Ley 18.455 , que establece que para la creación de las denominaciones de origen es necesario un Decreto Supremo expedido a través del Ministerio de Agricultura. No obstante esto, la denominación de origen Pisco ha sido establecida directamente por dicha ley, reiterando la misma forma de reconocimiento que tuvo desde sus orígenes.

Sin intención de restar importancia a otras denominaciones del origen, es posible afirmar que el Pisco goza de un reconocimiento de primer nivel dentro de nuestra jerarquía de las normas, ya que haber sido establecido en virtud de una ley, pone a esta materia sólo por debajo de aquellas que son objeto de Leyes Orgánicas constitucionales o de Leyes de Quórum calificado y por supuesto y como es lógico, de la Constitución, alero bajo el cual deben estar todas las normas para poder integrar el ordenamiento jurídico.

La consecuencia de este reconocimiento por vía legal, es que no es posible alterar la denominación de origen Pisco, por una norma que tenga rango inferior al legal, lo cual da una mayor consistencia a esta denominación de origen y, en el plano práctico se traduce en una seguridad para los inversionistas.

\section{b) Es inmutable}

Esta característica se relaciona de alguna forma con lo señalado del reconocimiento legal y la posibilidad de modificar la denominación de origen Pisco. En este sentido, el artículo 28 de la Ley 18.455 que establece el actual Libro Primero de la Ley de Alcoholes, señala en su inciso final que el Presidente de la República no podrá alterar, modificar ni suprimir las denominaciones de origen establecidas por la misma ley, entre las cuales figura la de Pisco, o las que se creen por la vía de un Decreto Supremo expedido a través del Ministerio de Agricultura. En esta limitación impuesta al Presidente de la República, la doctrina ha visto una suerte de inmutabilidad de las denominaciones de origen, entre las cuales se destaca la de Pisco.

No obstante, la existencia del citado impedimento legal, cabe señalar que dicha prohibición relativa a poder modificar, suprimir o alterar una denominación de origen, sólo dice relación con la facultad que el Presidente de la República ejerce a través de un Decreto Supremo, por lo tanto no sería aplicable a la facultad que tiene el legislador. De lo anterior, se desprende que es jurídicamente posible suprimir una denominación de origen por medio de una ley que, por ejemplo, derogara el actual Libro Primero de la Ley de Alcoholes. Claro está, que toda esta elucubración pierde fuerza al ser confrontada con la realidad, por cuanto es claro que la intención tanto del Ejecutivo como del Legislativo siempre ha sido reforzar el tema de las denominaciones de origen.

Con todos estos antecedentes es posible establecer que, si bien no son inmutables, las denominaciones de origen gozan de una gran estabilidad jurídica, avalada, ya sea por la prohibición establecida en la Ley de Alcoholes, o por la voluntad de gobernantes y legisladores tendiente a perfeccionarlas, más que a retroceder en su regulación. 


\section{c) Su uso indebido está sancionado}

Como es propio de un sistema jurídico, existe la posibilidad de sancionar a aquellos individuos que no respeten las normas impuestas por el mismo.

En el campo de las denominaciones de origen no se rompe esa regla, por cuanto el legislador ha establecido disposiciones que prohiben el uso de las denominaciones de origen para designar otros productos que los amparados por aquellas $\mathrm{y}$, en caso de que esta norma sea quebrantada, se aplicará una sanción pecuniaria al infractor, la cual según el artículo 45 de la Ley de Alcoholes puede ir desde 15 hasta 150 unidades tributarias mensuales. Además esta sanción también se aplica para el caso de que se vendan productos falsificados que no sean tóxicos o dañinos para la salud. Este punto, de la posibilidad de represión en relación con las denominaciones de origen, será analizado más en detalle, al tratar de las responsabilidades derivadas del uso de la institución en estudio.

\section{d) Es un plus a la inversión que favorece a las Regiones III y IV}

Siempre ante la posibilidad de destinar sus recursos, los inversionistas preferirán aquellas áreas que le reporten el mayor beneficio de acuerdo al capital destinado al negocio. Sin embargo, en el caso del Pisco, esa ecuación se ve alterada por una variable que no está contemplada al estudiar los costos de inversión, ya que es una ventaja o plus gratuito que viene incorporado al invertir en empresas relacionadas con la denominación Pisco, ya que esta representa toda una calidad y tradición. Si pudiéramos hacer una analogía, este plus es una especie de derecho de llaves que se incorpora a las inversiones en la industria pisquera.

Por lo anterior, es claro que ante la posibilidad de invertir en la actividad vitivinícola, es un elemento interesante el considerar la ventaja que representa que, el producto esté favorecido por una denominación de origen.

Como receptores directos de las decisiones que se tomen en el tema, están los habitantes de la Tercera y Cuarta Regiones de nuestro país. Son ellos quienes se ven favorecidos por el desarrollo de la industria pisquera, ya que esta implica fuentes de trabajo en el ámbito industrial y, por supuesto en el agricola; teniendo actualmente un importante crecimiento el turismo relacionado con la actividad Pisquera. Todos estos beneficios que actualmente gozan, las regiones comprendidas en la zona pisquera, se pueden ver multiplicados con una mejor regulación de las denominaciones de origen y especialmente la del Pisco.

\subsection{TITULAR DE LA DENOMINACIÓN DE ORIGEN PISCO}

Es de vital importancia determinar quien es el titular de la denominación de origen Pisco, es decir quien tiene la propiedad sobre este bien inmaterial, ya que será el titular de la misma el que podrá ejercer las facultades que otorgue el dominio de dicho bien.

Por otro lado, es relevante conocer a los detentadores de la denominación para saber a quien remitirse en caso de cualquier relación jurídica que pueda surgir por el uso 
de la misma. Como estos, son muchos los factores que se ven vinculados con la titularidad de la denominación de origen Pisco, por lo tanto es necesario esclarecer la materia al respecto.

La primera de estas posibilidades de titularidad, está dada por aquellos que piensan que el titular de toda denominación de origen es el Estado, como pasa, por ejemplo, en México, donde la titularidad del Estado sobre todas las denominaciones de origen tiene una consagración normativa en la Ley de Fomento y Protección de la Propiedad Industrial, la cual señala que el Estado de México es el titular de la denominación de origen. Esta sólo podrá usarse mediante autorización que expedida por el Instituto Mexicano de la Propiedad Industrial

Como en el caso mexicano, cuando sea el Estado el titular de las denominaciones de origen debe existir siempre un sistema para que, a través de los órganos que correspondan, se otorguen permisos para usar las denominaciones de origen. Frente a este punto cabe establecer qué tipo de institución jurídica sería la que habilitaría a un particular para usar una denominación, y en nuestro sistema legal puede ser, como ya se señaló, por vía de un permiso o bien de una concesión; esto como primera interrogante.

En relación con lo anterior, es necesario proyectarse respecto a qué órgano de la estructura estatal sería el competente para tratar el tema de las denominaciones de origen. No debemos olvidar que en nuestro ordenamiento administrativo es de frecuente ocurrencia, más de lo deseable, que existan varios órganos con competencia sobre la misma materia. Todo esto sin considerar los problemas de burocracia y eventual corrupción que puedan estar presentes en el aparato estatal.

Favorablemente para el caso de la denominación de origen Pisco, la realidad no es tan dramática como la que se ha planteado más arriba, ya que en nuestro sistema existe un convencimiento que el titular de la denominación de origen no es el Estado.

Paralelamente a la teoría de que podría ser el estado el titular de la denominación de origen, están aquellos que piensan que los titulares del dominio sobre este bien inmaterial son los particulares, específicamente los habitantes de la zona en la cual se elabora el producto amparado.

Con un criterio bastante acucioso, es posible señalar que en relación con nuestro derecho esta posibilidad de que todo un grupo de personas posea este bien inmaterial en común sería el ejemplo típico de una comunidad. Esto en virtud de lo consagrado por el artículo 2.304 del Código Civil, que señala que existe comunidad cuando dos o más personas poseen algo en común sin que hayan pactado sociedad o celebrado otro tipo de relación relativo a la misma cosa. El problema de este postulado es que se trataría de una comunidad muy sui generis, ya que la posesión en común de un bien por varias personas, por muchas que estas sean, implica tenerlas identificadas a todas, para así establecer quienes tienen la condición de comuneros. Como éste, son muchos más los inconvenientes que obstan a la posibilidad de considerar una comunidad, en el estricto sentido legal, en los habitantes del territorio en el cual se elabora el Pisco.

Superando lo anterior y entendiendo como comunidad, para el caso del $\mathrm{Pisco}$, a los habitantes de las Regiones III y IV. aún se presenta el problema de que el ver a esta "comunidad" como titular del dominio sobre la denominación Pisco implica una suer- 
te de indefinición en la materia, que en nada ayuda a contestar las interrogantes planteadas al comenzar este apartado.

Entendiendo que, en términos muy generales, no está mal considerar a toda la comunidad como titular de la denominación de origen Pisco, es más acertado decir que son los productores de Pisco, los verdaderos dueños de dicho bien; y si se dice que en términos generales es posible referirse a toda la comunidad, es porque todos tiene la posibilidad de iniciar la producción de Pisco, cumpliendo por supuesto las requisitos jurídicos necesarios. Justamente uno de estos requisitos está señalado en el artículo 13 inciso segundo de la Ley 18.445 , el cual señala que "los productores, elaboradores, envasadores, importadores, exportadores y comerciantes de productos (entendiendo para los efectos de dicha ley como productos, a los alcoholes etílicos, bebidas alcohólicas, subproductos alcohólicos y vinagres, además de los mostos, zumos y caldos destinados a la fermentación de los primeramente nombrados) y aquellas personas que en el ejercicio de su actividad utilicen alcohol etílico no desnaturalizado para fines distintos de la bebida, deberán inscribirse en los registros que para tal efecto establezca el servicio (Servicio Agrícola y Ganadero)".

Concordante con lo anterior, el Reglamento de la Ley 18.455 señala que la referida inscripción debe realizarse acompañando la declaración jurada de inicio de actividades y dentro de los treinta días siguientes al otorgamiento de la misma

De lo anterior, es posible inferir que, los titulares de la denominación de origen $y$, por tanto los propietarios de este bien inmaterial, son los productores de Pisco que se encuentren inscritos como tales en los registros del Servicio Agrícola y Ganadero. Ello sin olvidar que la intención al hacer esta especificación, respecto a los titulares de la denominación Pisco, es obtener algún grado de certeza en relación a las personas o entidades que puedan figurar como titulares de dicha denominación ante cualquier gestión que diga relación con la misma.

En el fondo se trata de una cuestión de eficacia jurídica, ya que la mejor forma de ejercer un derecho es teniendo certeza respecto a su titularidad. por lo tanto, es posible señalar que los productores de Pisco, debidamente registrados, son los titulares inmediatos de la denominación de origen Pisco, mientras que el resto de la comunidad de las Regiones III y IV, son los titulares mediatos de la misma.

Esta calidad de titulares mediatos del resto de la comunidad, implica que ellos se ven beneficiados con la existencia de la denominación, es claro que a todas las comunidades de la zona pisquera, les favorece el desarrollo de la industria, pero por otro lado implica que su labor es pasiva, en cuanto a cumplir con las obligaciones que, se imponen a los productores como titulares directos. Sin embargo, esta realidad puede cambiar frente a una nueva regulación de las denominaciones de origen que, considere cuerpos colegiados para su gestión, ya que es perfectamente posible que, los hasta ahora, titulares mediatos cobren un rol más activo en la dinámica de la denominación de origen Pisco. Es posible pensar, por ejemplo, que las organizaciones territoriales o funcionales de carácter vecinal, que puedan estar representadas en los órganos que se creen para regular la denominación Pisco, se comprometen a desarrollar determinadas actividades para beneficiar la denominación y darle un mayor prestigio y tradición, $v$.gr. organizar una fiesta de la vendimia. 
Sin perjuicio de lo que se pueda tratar más adelante, es necesario señalar que, el actual sistema de registro de productores que se lleva en el Servicio Agrícola y Ganadero, no parece ser idóneo para el desarrollo de la denominación de origen Pisco. Ello es así, por que este registro es común para los productores señalados en el artículo 13 de la Ley 18.455 , frente a lo cual se pierde el aspecto distintivo y diferenciador que debería existir en todo el tratamiento de las denominaciones de origen. Además, la exigencia legal es sólo un registro, sin imponer mayores requisitos que la declaración de iniciación de actividades. En contraposición a este sistema, muy permisivo, es posible plantear uno distinto, en el cual se establezcan estrictos requisitos para ser admitido como productor de Pisco, de manera que aquel que los cumpla esté consciente que tiene una enorme responsabilidad como titular de la denominación de origen.

\subsection{FACULTADES DERIVADAS DEL DOMINIO DE LA DENOMINACIÓN DE ORIGEN PISCO}

Una vez establecido que los titulares del dominio sobre la denominación de origen Pisco son los productores del mismo debidamente inscritos, es necesario revisar qué características presentan en este caso particular las facultades del dominio.

Como ya se ha establecido en este trabajo, al tratar la naturaleza jurídica de las denominaciones de origen, está claro que sobre los bienes inmateriales existe la posibilidad de ejercer el dominio y que, esta forma de dominio presenta algunas peculiaridades en cuanto a las facultades derivadas del mismo, y el caso del Pisco no escapa a esta realidad de los bienes inmateriales.

En cuanto a la facultad de usar la denominación Pisco, es claro que quienes logren la titularidad de la misma podrán servirse de ella de acuerdo a su naturaleza. Por lo tanto, entendiendo que naturaleza como aquellas características propias del bien objeto del dominio, cabe especificar que la naturaleza de la denominación Pisco está dada por ser una institución jurídica que, identifica y da protección a una determinada clase de aguardiente, que se debe elaborar sólo en las Regiones III y IV y con las uvas provenientes de las variedades de vides que señala el reglamento ${ }^{\text {. }}$ plantadas en las mismas Regiones antes señaladas.

De todo lo anterior es posible señalar que, el uso de la denominación de origen Pisco se encuentra restringido por las limitantes normativas, lo cual es plenamente comprensible, si consideramos que desde los tiempos de la creación de la zona pisquera hasta nuestros días, la intención de toda la regulación sobre esta materia ha sido proteger un producto de calidad y, además estimular la economía de ciertas regiones del país.

Con relación a la facultad de gozar de la cosa, que implica el aprovecharse de los frutos y productos de ésta, en el caso de Pisco, como en de los bienes inmateriales en

9 Según el artículo 56 del reglamento de la ley 18.455, que ya ha sido cítado en esta misma obra, las variedades de uva con las que se puede fabricar el Pisco son las siguientes variedades de uva de la especie Vitis vinififera L.: Chasselas Musque Vrai, Moscatel Amarilla, Moscatel Blanca Temprana, Moscatel de Alejandría o Italia, Moscatel de Austria, Moscatel de Frontigan, Moscatel de Hamburgo, Moscatel Negra, Moscatel Rosada o Pastilla, Moscato de Canelli, Muscat Orange, Pedro Jiménez y Torontel. 
general, se presenta el problema que estos bienes no presentan la cualidad de poder generar frutos o productos. Por lo tanto es posible afirmar que la propiedad sobre la denominación de origen Pisco no otorga la facultad de poder gozar de ella, lo cual no es producto de un impedimento normativo, sino de la propia naturaleza de los bienes inmateriales. En nuestro derecho no cabe la posibilidad, por ejemplo, que los productores de Pisco puedan arrendar su denominación de origen a un productor de aguardiente de Petorca en la $\vee$ Región, situación que daría lugar que la denominación en cuestión rindiera frutos civiles.

La tercera facultad que se contempla ligada al dominio es la de disponer, en virtud de ella el dueño puede disponer de la cosa en forma material, por ejemplo destruirla, consumiéndola o transformándola; o bien se puede disponer en forma jurídica, lo que puede ocurrir cuando la transfiere o la grava con prenda o hipoteca. Todas estas situaciones no tienen ninguna posibilidad de ocurrir en el caso del dominio de la denominación de origen Pisco como un bien inmaterial, ya que los productores de Pisco, no tienen facultad para enajenarla o gravarla de modo alguno y por su propia característica de ser un bien de tipo intelectual, no existe la posibilidad de destruirlo. En resumen, la facultad de disponer no acompaña al dominio que existe sobre el Pisco como denominación de origen.

No obstante la imposibilidad de los productores de Pisco de poder disponer del bien inmaterial del cual son dueños, ellos se pueden ver afectados por un acto de la autoridad que les haga perder su dominio, este sería el caso de una nueva ley que derogara el actual Libro primero de la Ley de alcoholes, con lo cual se eliminarían las denominaciones de origen. Como los propietarios de la denominación de origen gozan de derechos adquiridos respecto de la misma, la supuesta ley derogatoria sería inconstitucional en cuanto no se ajustara a las normas establecidas por la Constitución, en su artículo 19 № 24 inciso tercero, para el procedimiento de expropiación.

Por lo tanto, los productores de Pisco, no obstante tener un dominio un tanto sui generis respecto a la denominación de origen que detentan, de todas maneras se encuentran plenamente protegidos por nuestra Carta Fundamental ante cualquier atentado contra su propiedad por parte de la autoridad o de los particulares. Tanto es así, que es perfectamente aplicable el Recurso de Protección, establecido en el artículo 20 de la Constitución para proteger de toda privación, perturbación o amenaza la propiedad sobre el bien inmaterial constituido por la denominación de origen Pisco.

\section{ASPECTOS QUE DEBERÍAN SER CONSIDERADOS PARA MEJORAR LA DENOMINACIÓN DE ORIGEN DEL PISCO CHILENO}

El objetivo de esta parte de la investigación es dar a conocer aquellos aspectos que, figuran como necesariamente perfectibles, para poder mejorar la doble función de la denominación de origen Pisco; por una parte la de identificar un noble producto chileno y, por otra la dar protección al mismo. Cabe señalar, que todas las ideas recogidas en este punto reflejan el sentir de los distintos actores de la actividad pisquera, ideas que vienen apuntando desde hace tiempo a la elaboración del reglamento que según el artículo 55 del Reglamento de la Ley de Alcoholes, debería determinar las condiciones, características y modalidades a cumplir por las zonas vitícolas y las deno- 
minaciones de origen de vinos y destilados; norma que hasta el momento no ha sido dictada.

\section{¿Creación de Órganos Administradores de la Denominación de Origen Pisco?}

Actualmente, todo el tema de las denominaciones de origen en nuestro país está regulado básicamente por las normas que, se encuentran contenidas en la Ley de Alcoholes y su Reglamento. La única disposición que ha complementado las ya nombradas, es el Decreto 464 de Agricultura que establece la Zonificación Vitícola, el cual, como ya se ha tratado, es de aplicación limitada a los vinos y además presenta una redacción que en nada ayuda perfeccionar la regulación de las denominaciones de origen.

Frente a esta realidad, es posible afirmar que, ningún cuerpo normativo ha establecido un sistema funcional que permita tener una administración de las denominaciones de origen tendiente a fomentarlas y a mejorarlas. Como parte de dicho sistema debería considerarse la creación de entidades que agrupen a todos los interesados en el tema y en el caso especial del Pisco, dicha entidad debería ser la representante oficial de los titulares de dicha denominación.

\section{a) Órganos a nivel nacional}

Para el tratamiento de todas las cuestiones relativas a las denominaciones de origen en nuestro pais, debería existir un órgano colegiado con competencia nacional. El primer problema a resolver con respecto a dicho órgano, que podría llamarse Instituto Chileno de las Denominaciones de Origen, se refiere al nivel de dependencia que éste debiera tener con el Estado. Al respecto las propuestas son claras, por un lado el Instituto podría estar bajo la dependencia del Ministerio de Economía; por otro lado se propone que el mencionado Instituto sea un ente privado que admita la participación de representantes del Gobierno.

La opción más adecuada parece ser la primera, ya que si se trata de regular el tema a nivel nacional, es necesario que el ente encargado disponga de la estabilidad y respaldo que le otorgan el ser parte del aparato estatal. En este sentido, el citado Instituto, debería revestir la forma de una persona jurídica de Derecho Público, del tipo de las referidas en el artículo 547 del Código Civil. Más específicamente, el Instituto Chileno de las Denominaciones de Origen se conformaría como una corporación de Derecho Público con personalidad jurídica y patrimonio propio, dependiente, como se ha señalado del Ministerio de Economía. Cabe tener presente, que esta opción presenta como problema la carga de burocracia e ineficiencia propia de los órganos estatales.

Por lo tanto, si el Instituto dependiera del Ministerio de Economía, es natural que al presidente del mismo lo nombre el Presidente de la República y sea de su exclusiva confianza. Además del presidente, el Instituto debe estar formado por una planta de personal idónea para administrar el tema de las denominaciones de origen. Con respecto a esto, se plantea que, la posibilidad que el Instituto pueda contar con un consejo consultivo formado por representantes de las diversas denominaciones de origen que existan en el país. Dicho consejo consultor, debería ser el ente que se encargue de mantener el contacto entre el Instituto y los titulares de las denominaciones existentes, con lo cual se facilitaría el trabajo de los funcionarios del Instituto, permitiendo así una gestión más eficiente del mismo. 

guientes:

Entre las principales funciones que debería tener el instituto se destacan las si-

1.- Velar por el cumplimiento de todas las disposiciones legales y reglamentarias que sean aplicables a cada denominación de origen dentro del país. Esto implica que, ante la posibilidad que se establezcan normas nacionales aplicables a denominaciones de origen extranjeras para que puedan operar en Chile, el Instituto tendría la facultad para fiscalizar que dichas denominaciones foráneas cumplan las regulaciones chilenas.

2.- Velar por el prestigio de cada denominación de origen, persiguiendo su uso indebido. Esta función está estrechamente ligada con la anterior y transforma al Instituto en una especie de ministerio público encargado de perseguir las violaciones a las normas que regulan las denominaciones de origen.

3.- Informar al Presidente de la República respecto a los temas vinculados con las denominaciones de origen.

4.- Proponer al Presidente de la República el establecimiento de denominaciones de origen. Estas proposiciones pueden ser producto de sus propios estudios o bien de las solicitudes que terceros puedan hacer llegar al Instituto respecto a la necesidad de establecer una nueva denominación.

5.- Representar al pais a nivel internacional, en todo tipo de reuniones vinculadas al tema de las denominaciones de origen.

6.- Crear y mantener catastros de las distintas denominaciones de origen que existan en el país, con especial referencia a los productores que se encuentran registrados dentro de cada denominación. Esta estadística permitirá al Instituto tener un conocimiento directo de quien o quienes son los titulares de cada denominación, lo cual permitiría una mejor función de control e información de las políticas del Instituto. de origen.

7.- Fomentar los estudios que permitan mejorar el tema de las denominaciones

Estas son algunas de las funciones que debería tener el Instituto Chileno de las Denominaciones de Origen para llevar cabo eficientemente su labor y así contribuir a dar al tema de las denominaciones de origen la importancia que este se merece, especialmente como una vía de desarrollo económico para el país.

\section{b) El Instituto del Pisco ${ }^{10}$}

Es propio de toda denominación de origen, el tener un consejo regulador encargado de velar por la calidad del producto y por el cumplimiento de las normas que atañen específicamente a ese producto amparado. En el caso del Pisco, hay una coincidencia entre todos los involucrados en su producción que, dicho consejo regulador debería adoptar el nombre de Instituto del Pisco. En el caso del Instituto del Pisco, no cabe duda que este organismo debe ser de conformación privada con una participación gubernamental. La forma que el Instituto del Pisco debería adoptar es la de una corporación de Derecho Privado, especie de persona jurídica que se encuentra regulada por los 
artículos 545 y siguientes del Código Civil, además del reglamento sobre la concesión de personalidad jurídica a corporaciones y fundaciones, publicado en el Diario Oficial el 20 de Marzo de $1979^{11}$

El objetivo, el Instituto del Pisco sería preocuparse de la administración de la denominación de origen Pisco. Respecto a esto, conviene aclarar que todas las gestiones que pueda desarrollar el Instituto del Pisco, para el correcto funcionamiento de la denominación de origen que resguarda, sólo serán de carácter obligatorio para sus asociados. Para estos efectos, se debe tener presente que nuestra Carta Fundamental, en su artículo $19 \mathrm{~N}^{\circ} 15$, al garantizar la libertad de asociación, establece que nadie puede ser obligado a pertenecer a una asociación.

Para su óptimo funcionamiento, el Instituto del Pisco debería contar con un cuerpo directivo y, con los funcionarios operativos que fueran necesarios para implementar en la práctica las medidas tomadas por el cuerpo directivo. En este sentido, dicho cuerpo debería estar formado por representantes de los productores de vides pisqueras, representantes de los envasadores de Pisco, representantes del gobierno ( idealmente del Instituto Chileno de Denominaciones de Origen ) y por representantes de la comunidad de las Regiones III, de Atacama y IV, de Coquimbo.

Conformado de esta manera, que permite la participación de todos los sectores involucrados en la denominación de origen Pisco, el Instituto del Pisco debería erguirse como la entidad que velare por los intereses de la industria pisquera. En el fondo, este Instituto sería el legítimo representante de los titulares de la denominación de origen Pisco y como tal, sería la voz oficial de los mismos ante cualquier tipo de relación jurídica que implicara a la denominación Pisco como tal y no sólo a una determinada marca que haga uso de la misma.

Las funciones que corresponderían al Instituto del Pisco son una especificación de las que corresponden al Instituto Chileno de las Denominaciones de origen, por lo tanto se deben entender como funciones del Instituto del Pisco todas las relacionadas con vigilar el cumplimiento, por parte de sus asociados, de las disposiciones legales y reglamentarias que se apliquen al caso, además y en particular deberían ser algunas funciones del Instituto del Pisco las siguientes:

1.- Designar un representante para que actúe como miembro del consejo consultor del Instituto Chileno de las Denominaciones de Origen.

2.- Establecer los requisitos especiales que deban cumplir los productores de aguardiente de las Regiones III de Atacama y IV de Coquimbo para ser admitidos como miembros del Instituto del Pisco.

3.- Orientar y vigilar la producción de Pisco, poniendo especial énfasis en implementar estándares de calidad uniformes que deban ser exigidos a todos los productores de Pisco.

4.- Crear y mantener actualizado un registro con los productores que integren el Instituto del Pisco.

11 Diario Oficial N*30.319 
5.- Elaborar políticas de promoción del Pisco basadas en la importancia de contar con una denominación de origen. Esta función es muy importante, ya que a través de ella se puede conseguir crear en los consumidores un mayor conocimiento de la calidad que va implícita en un producto amparado con una denominación de origen.

6.- Promover la investigación en el campo de la industria pisquera, tanto a nivel industrial como agrícola.

Para el cumplimiento de estas y otras funciones, se ha propuesto que el Instituto del Pisco se divida el secciones o departamentos, entre los cuales cabe destacar el departamento de control y represión de fraudes, el departamento de investigación y desarrollo del Pisco y el departamento de promoción del Pisco.

Con esta forma de organización y cumpliendo las funciones señaladas, más las que sean necesarias, el Instituto del Pisco se presenta como una de las aspiraciones más profundas de los productores de Pisco, ya que a través de este organismo se podría lograr el verdadero desarrollo de la industria pisquera.

\section{CONCLUSIÓN}

Una vez que han sido estudiados diversos aspectos relativos a las denominaciones de origen, es posible afirmar que si bien existe una concordancia doctrinaria en cuanto a su importancia y valor como instrumento identificador de productos, también es claro que en la práctica no se ve reflejado ese convencimiento de su utilidad. Si bien, esta no es una realidad mundial, si lo es, lamentablemente, en el caso chileno y en el de otros países del llamado "Tercer Mundo".

No obstante estos aspectos negativos, es posible inferir del presente trabajo que las denominaciones de origen se presentan como la especie de indicaciones geográficas que, mejor se ajustan a los fines de servir de apoyo a un determinado producto $y$, de paso a la región en la cual éste se produce o se elabora. Una de las ventajas de las denominaciones de origen, es que son aptas para establecer sistemas que vinculan aspectos jurídicos, económicos, sociales y culturales. Es, en esta confluencia, donde la calidad del producto figura como un nexo que permite la generación de diversas relaciones jurídicas entre los aspectos ya nombrados.

En este sentido, queda claro que la presencia de una denominación de origen es un fuerte estímulo a la inversión en determinados sectores de un país, lo cual representa una ventaja para los Estados si consideramos que esta forma de promoción a la actividad económica no implica un gasto para el Fisco, como sería el caso de un subsidio; ni tampoco representa la renuncia a ingresos por parte del Estado como pasa en los casos de las zonas francas o como resultado de un contrato ley. Ahora bien, todos los beneficios derivados de reconocer a una zona con el establecimiento de una denominación de origen, tienen una repercusión directa en los niveles de empleo, ya que, más inversión significa bajar los índices de cesantía, lo cual, obviamente es avanzar un poco más en el logro del Bien Común.

En relación con los intereses económicos de los productores, el establecimiento de las denominaciones de origen representa una ventaja inigualable, ya que les permite ingresar al mercado con una ventaja sobre los demás productos. Esta realidad es especialmente importante en el campo de la vitivinicultura, donde cualquier elemento que 
sea indicativo de una calidad superior, piénsese en años de guarda, modos de producción o el gozar de una denominación de origen; significa el tener una mejor posición dentro del mercado y una percepción más favorable por parte de los consumidores.

En este último punto, es donde se presentan algunas dificultades para el Pisco chileno. Al parecer, la falta de productos, del mismo nivel que el Pisco, que compitan con él, ha repercutido en que la garantía de estar amparado con una denominación de origen no sea mayormente explotada por parte de los productores. En este sentido, parece ser que existe una conformidad con el hecho de tener el derecho de producción exclusiva del Pisco dentro de las Regiones III de Atacama y IV de Coquimbo; por lo cual no se ha progresado en el desarrollo de la denominación y, mucho menos en la explotación de este régimen de amparo como un efectivo elemento de marketing. No obstante esta posición, un tanto aletargada, de los productores debería ser modificada ante el inminente ingreso del Pisco al mercado mundial, donde las denominaciones de origen sí tienen una real importancia como instrumentos de protección e identificación de productos.

En el aspecto jurídico, la realidad no deja de ser de dulce y agraz, ya que luego de un desarrollo notable del tema desde la década del treinta, se ha llegado a un estancamiento legislativo de mas de diez años, que se hace patente con la carencia del reglamento que debería regular específicamente el tema de las denominaciones de origen en nuestro país, según lo dispone el artículo 55 del reglamento de la Ley 18.455 , ley que establece el nuevo Libro Primero de la Ley de Alcoholes. Con respecto a esta situación, es posible concluir que la promulgación del Decreto 464, de 14 de Diciembre de 1994 , del Ministerio de Agricultura, no completa este vacío, ya que éste, como se analizó en su oportunidad, confunde los términos y además no presenta una regulación aplicable a todas las denominaciones de origen, sino sólo a las del Vino.

Esta actitud poco activa del poder ejecutivo se suma a la dejación del país en el ámbito internacional, ya que no se ha concurrido a ratificar diversos acuerdos que regulan la materia, como por ejemplo el Arreglo de Madrid o el Arreglo de Lisboa.

Frente a esta actitud pasiva, cobra gran importancia la teoría que establece que las denominaciones de origen son bienes inmateriales, por cuanto cualquier nueva acción por parte del legislador o bien del gobierno, con respecto a las denominaciones de origen, debe considerarles la referida naturaleza jurídica con todos los alcances patrimoniales que esto implica. En estos últimos se comprenden, el ejercicio del derecho de propiedad sobre las denominaciones, lo cual implica la garantía constitucional de esta especie de propiedad y por supuesto la posibilidad de aplicarle el recurso de protección. Además se debe considerar que en caso de derogación de las normas que establecen las denominaciones de origen, se debe proceder conforme a las normas de la expropiación de bienes.

Por tanto, cabe concluir, que las denominaciones de origen son un efectivo medio para la protección e identificación de productos y que en especial en el caso del Pisco chileno, esta realidad se presenta como un elemento que actualmente se encuentra subvalorado por los productores del mismo. En este sentido, cualquier acción que se tome por revertir esta situación debe, considerar la implementación de una adecuada regulación de la materia. 
Además, no es posible progresar en el tema de las denominaciones de origen, en general, y en el caso del Pisco, en particular, sin una adecuada institucionalidad que canalice los intereses de los diversos interesados en la materia, en este sentido cobra vital importancia el desarrollo que pueda alcanzar el Instituto del Pisco, el cual como consejo regulador debería ser el ente de primera línea encargado de velar por los intereses de la industria pisquera y por sobre todo por el desarrollo de la denominación de origen pisco.

Si bien el tratar el tema en la perspectiva de otras áreas no es el tema de esta tesis, es preciso reconocer que en nuestro país existen algunos productos con inmejorables condiciones para constituir denominaciones de origen, por ejemplo: los limones de Pica, las aceitunas de Azapa o del Huasco. Estos últimos dos ejemplos son de relevancia si pensamos en la industria de los aceites y sus derivados de tan notorio desarrollo en Europa y que en nuestro país se encuentran en vías de crecimiento.

Como es posible apreciar las denominaciones de origen no son un tema que pueda ser dejado a sus suerte sobre todo por la ventaja económica que ellas reportan especialmente si se consideran desde el punto de vista del comercio internacional y de la posible educación de los consumidores a nivel interno. 